Review Article

\title{
DONKEY ANAPHORA AND DYNAMICS OF JAPANESE PRONOUNS
}

\author{
IKUMI IMANI \\ Nagoya Gakuin University*
}

\begin{abstract}
Dynamics of Meaning: Anaphora, Presupposition, and the Theory of Grammar, by Gennaro Chierchia, University of Chicago Press, Chicago, 1995, xv+270pp.
\end{abstract}

\section{Introduction}

The study of donkey pronouns has generated an extensive research on anaphora and quantification. Since classical discourse representation theory (DRT) and file change semantics (FCS) launched into a semantic treatment of anaphoric binding in the early 80 's, it has been a methodological change from a static view of semantics to a dynamic one that has implicitly or explicitly prompted a new understanding of anaphoric binding. The leading idea in dynamic semantics is that "the meaning of a sentence does not lie in its truth conditions, but rather in the way it changes (the representation of) the information of the interpreter" (Groenendijk and Stokhof (1991)). The book under review is an intriguing attempt, with a dynamic perspective to build a framework for accounting for a wide range of linguistic phenomena. Technically, Chierchia incorporates into his approach insights from the recent development of semantics such as dynamic predicate logic (DPL: Groenendijk and Stokhof $(1990,1991))$ and generalized quantifiers approach (GQA: Barwise and Cooper (1981)) as well as DRT (Kamp

* I would like to thank Paul McGrath, Barry Schein, Ayumi Ueyama, Maki Watanabe and Dag Westerståhl for their valuable comments and suggestions. This work was supported in part by a Grant-in-Aid for Scientific Research from the Japanese Ministry of Education, Grant No. 08044009, and also supported in part by a research grant in 1997 from Nagoya Gakuin University. 
(1981) and Kamp and Reyle (1993)) and FCS (Heim (1982)). In this review, I will outline Chierchia's proposals and discuss some problems in his work. I will also suggest the direction of some possible extensions that include Japanese anaphora in the last section.

\section{Dynamics of Binding}

There are cases where anaphoric links cannot be explained by the standard first-order predicate logic (PL). Donkey sentences such as (1) and (2) are classical examples where PL fails to deliver their proper translations.

(1) Every farmer who owns a donkey beats it.

(2) If a farmer owns a donkey, he beats it.

If we use PL in translating (1) and (2) in a compositional way, under the assumption that anaphoric pronouns are represented as bound variables, ${ }^{1}$ we get the following (preferred) translations, respectively:

( 3 ) $\forall x[[\operatorname{farmer}(\mathrm{x}) \wedge \exists \mathrm{y}[\operatorname{donkey}(\mathrm{y}) \wedge \operatorname{own}(\mathrm{x}, \mathrm{y})]] \rightarrow \operatorname{beat}(\mathrm{x}, \mathrm{y})]$

(4) $\exists x[\operatorname{farmer}(\mathrm{x}) \wedge \exists \mathrm{y}[\operatorname{donkey}(\mathrm{y}) \wedge \operatorname{own}(\mathrm{x}, \mathrm{y})]] \rightarrow \operatorname{beat}(\mathrm{x}, \mathrm{y})$

But (3) and (4) do not represent proper meanings of (1) and (2), because the last occurrences of variables $x$ and $y$ in (4), and $y$ in (3) are not bound by the quantifiers in the antecedents. The proper translation of (3) and (4) is (5): ${ }^{2}$

( 5$) \quad \forall \mathrm{x} \forall \mathrm{y}[[\operatorname{farmer}(\mathrm{x}) \wedge \operatorname{donkey}(\mathrm{y}) \wedge \operatorname{own}(\mathrm{x}, \mathrm{y})] \rightarrow \operatorname{beat}(\mathrm{x}, \mathrm{y})]$ Since problems of this kind in PL were pointed out, many attempts have been devoted, under the name of dynamic semantics, to accounting for a binding mechanism that extends scope over a syntactic binding (e.g. defined by c-command). Chierchia's approach is posited in this stream.

Pronouns, whether anaphoric or not, have traditionally been taken as individual variables. DRT, FCS and DPL follow suit. However, it is not always so. See van der Does (1996) for another way of dealing with anaphoric pronouns under a version of the E-type approach.

2 There are some revised versions of PL, where donkey pronouns are bound by the universal quantifier without giving up compositionality. See Pagin and Westerståhl (1993). 


\section{Context Change Potentials}

To formalize the scope extension over a syntactic binding, Chierchia introduces the idea of context change potentials (CCPs), which is based on the idea of changing files as in FCS (Heim (1982)). The context change potential of $S$, represented by $\left[S^{\prime} \wedge p\right.$ ], is the set of alternatives that remains open after $S$ has been uttered, where ' $p$ ' is a place holder for possible continuations. ${ }^{3}$ The intuitive idea of $[S$ ' $\wedge p$ ] is that ' $p$ ' plays a role to carry over (the content of) $S$ ' to subsequent sentences. Let's consider (6), where a pronoun is not syntactically bound by an antecedent.

(6) a. A man walks in the park. He whistles.

b. $\exists x[\operatorname{man}(x) \wedge$ walk-in-the-park $(x) \wedge p]$

c. $\quad$ whistle $(x) \wedge p$

By means of replacing ' $p$ ' in (6b) with (6c), we get (7).

( 7$) \exists x[\operatorname{man}(x) \wedge$ walk-in-the-park $(x) \wedge$ whistle $(x) \wedge p]$

(7) carries ' $p$ ' for other possible continuations, and 'he' is bound by the existential quantifier that has wide scope over the sentential boundary.

To embody the idea of context change potentials he uses a modified version of intensional logic (IL). Chierchia's IL is just like Montague's IL, except for the dynamic treatment of 'types' and 'propositions.' The type of a context change potential of $S,\left[S^{\prime} \wedge p\right]$, is represented by $c c(=<<\mathrm{s}, \mathrm{t}\rangle, \mathrm{t}\rangle)$. For example, the type of 'run' is $\langle\mathrm{e}, \mathrm{cc}\rangle$ in his framework, while it is $\langle\mathrm{e}, \mathrm{t}\rangle$ in the standard Montague grammar (MG). He restricts the role of intensions to assigning values to variables. In accordance with the restriction of intensions to assignments, a proposition ${ }^{\wedge} \varphi$ (where $\varphi$ is a formula) is the set of assignments with respect to which $\varphi$ is true, while it is the set of worlds in MG. "', is abstraction over assignments, and " $"$ application to the current assignment. Chierchia also defines $\uparrow$ - and $\downarrow$-operators. $\uparrow$ maps a proposition into the corresponding CCP, as shown in (8).

${ }^{3}\left[\mathrm{~S}^{\prime} \wedge \mathrm{p}\right]$ corresponds to $\left[\mathrm{S}^{\prime}+\right]$ in Heim $(1982)$.

4 Basic types in IL are $e$ for 'entity' and $t$ for 'truth value.' Expressions of type $e$ are terms, while expressions of type $t$ are well-formed formulae. Complex types are represented as $\langle a, b\rangle$, where $a$ and $b$ are types. Each extensional type $a$ has an intensional correlate $\langle s, a\rangle$. An expression of type $\langle s, a\rangle$ has as its semantic value an intension. 
(8) $\uparrow \varphi=\lambda p[\varphi \wedge$ p $]$,

where $\uparrow \varphi$ is a function that accepts all and only the propositions that are compatible with $\varphi$ 's truth. On the other hand, $\downarrow$ maps a CCP into the corresponding static proposition.

(9) $\downarrow \mathrm{A}=\mathrm{A}\left({ }^{\wedge} \mathrm{T}\right)$,

where $\mathrm{A}$ is a context change potential and $\mathrm{T}$ is something uninformative like a tautology. A static content of a sentence is given by means of filling a place holder with T. (10) is an example of (9).

(10) $\downarrow \lambda p[\varphi \wedge p]=\lambda p[\varphi \wedge p](\wedge \mathrm{T})=\varphi \wedge \mathrm{T}=\varphi$ Note that $\downarrow \uparrow \mathrm{A}=\mathrm{A}$, but $\uparrow \downarrow \mathrm{A} \neq \mathrm{A}$.

In dynamic semantics it is a general assumption that existential quantifiers and conjunctions are dynamic operators with which sentences have context change potentials. Chierchia makes this assumption, and provides the following definitions:

(11) a. $\mathrm{A} \wedge \mathrm{B}=\lambda p\left[\mathrm{~A}\left({ }^{\wedge} \mathrm{B}(p)\right)\right]$

b. $\exists \mathrm{x} \mathrm{A}=\lambda p \quad \exists \mathrm{x}[\mathrm{A}(p)]$,

where $\wedge$ and $\exists$ are what he calls a dynamic conjunction and a dynamic existential quantifier, respectively. ${ }^{5}$ Other operators are not dynamic in terms of CCPs. Some such operators are given in (12).

$$
\begin{aligned}
& \text { a. } \neg \mathrm{A}=\uparrow \neg \downarrow \mathrm{A} \\
& \text { b. } \forall \mathrm{x} \mathrm{A}=\sqsupset \exists \mathrm{x} \neg \mathrm{A}
\end{aligned}
$$

\section{1. $\forall$-readings and $\exists$-readings}

In the early stage of the study of donkey sentences, the main concern in the literature was to show how to deliver " $\forall$-readings" that donkey sentences have. However, since the late 80 's, " $\exists$-readings" in donkey sentences have come into focus. $\exists$-readings are readings in which indefinites have existential force when they are linked to pronouns. ${ }^{6}$ (13) is a well-known sentence where an $\exists$-reading is preferred:

(13) Every man who has a quarter in his pocket puts it in the parking meter.

(Schubert and Pelletier (1989))

\footnotetext{
5 When a sentence includes indefinites, a CCP changes the input context in terms of assignments (i.e. $\mathrm{g}[\mathrm{x} / \mathrm{u}]$ ). On the other hand, when it includes no indefinite, a CCP works as a 'test' (for more details, e.g. see Groenendijk and Stokhof (1991)).

6 In the literature, the terms, 'a strong reading' and 'a weak reading' are also widely used, as corresponding to 'a universal reading' and 'an existential reading, ' respectively.
} 
The $\forall$-reading analysis requires that for (13) to be true every man has to put every quarter in his pocket into the parking meter. But this is a little embarrassing. The preferred meaning of (13) is that every man puts at least one quarter in the parking meter. ${ }^{7}$

To see how $\exists$-readings can be delivered in Chierchia's approach, let's use (14) as our example. ((14) prefers a $\forall$-reading, but it is possible for (14) to have an $\exists$-reading, given an appropriate context (as for more details, see Chierchia (1995))). An $\exists$-reading of (14) is roughly represented as (15).

(14) Every farmer who owns a donkey beats it.

(15) Every farmer who owns a donkey owns a donkey and beats it.

The straightforward way to deliver (15) is to copy 'owns a donkey' in the relative clause into the verb phrase by means of an accommodation rule (or what Chierchia calls 'a copying rule'). However, as he points out, this procedure makes a wrong prediction about sentences like (16).

(16) *Every farmer who does not own a donkey wants to own it.

To overcome the problems with the accommodation rule, he introduces a dynamic conservativity into his framework. In GQA, NP denotations are analyzed as sets of sets and determiners like 'every' as relations between sets. Of the properties that these determiners have, the most universal one is 'conservativity' (i.e. $\mathrm{D}(\mathrm{X}, \mathrm{Y})=\mathrm{D}(\mathrm{X}, \mathrm{X} \cap \mathrm{Y})$ ). He defines a dynamic version of conservativity as in (17): ${ }^{8}$

(17) $\mathrm{D}^{\prime}(\mathrm{P}, \mathrm{Q})=\uparrow \mathrm{D}(\downarrow \mathrm{P})(\downarrow[\mathrm{P} \wedge \mathrm{Q}])$,

where (i) $\mathrm{P}$ and $\mathrm{Q}$ are of type $\langle\mathrm{s},\langle\mathrm{e}, \mathrm{cc}\rangle\rangle$, (ii) $\downarrow \mathrm{P}=\lambda \mathrm{x} \downarrow^{\vee} \mathrm{P}(\mathrm{x})$, and (iii) $\mathrm{P} \wedge \mathrm{Q}={ }^{\wedge} \lambda \mathrm{x}\left[{ }^{\wedge} \mathrm{P}(\mathrm{x}) \wedge{ }^{ } \mathrm{Q}(\mathrm{x})\right]$. (17) plays a role for what the accommodation rule does, and handles the difference of acceptability between (14) and (16).

Quantificational determiners are treated as in (18), based on (17), while the indefinite determiner, 'a,' is treated as in (19):

7 The classical E-type analysis also fares badly in dealing with (13). That is, for (13) to be true, every man (happens to) have the one and only one quarter in his pocket. But this is not a reading we usually expect (13) to have.

8 See Kanazawa (1994) about a stronger version of the definition of dynamic conservativity. 
(19) $\lambda \mathrm{P} \lambda \mathrm{Q} \exists \mathrm{x}\left[{ }^{\sim} \mathrm{P}(\mathrm{x}) \wedge{ }^{\sim} \mathrm{Q}(\mathrm{x})\right]$

The difference in the treatment of indefinites vs. quantificational determiners lies in the fact that only indefinites have a dynamic effect where sentences have context change potentials (i.e. $\exists x A=\lambda p \exists x[A(p)]$ ). It reflects the DRT assumption that indefinites introduce discourse referents (as 'pegs' for subsequent 'conditions'), ${ }^{10}$ while quantificational determiners do not.

Taking determiners as relations between (dynamic) properties, Chierchia's approach gets rid of the so-called proportion problem. In classical DRT, donkey sentences are interpreted as quantified over pairs. That is, determiners are regarded as unselective binders. An unselective binding works well for determiners like 'every' and 'no,' but when it comes to deteminers like 'most,' we run into trouble with truth conditions. (20) is such an example.

(20) a. Most farmers who own a donkey beat it.

b. $\operatorname{most}_{x, y}[\operatorname{farmer}(\mathrm{x}) \wedge \operatorname{donkey}(\mathrm{y}) \wedge \operatorname{own}(\mathrm{x}, \mathrm{y})][$ beat $(\mathrm{x}, \mathrm{y})]$ (20) is true in a model where there are two farmers and one of them has only one donkey and does not beat it, while the other has five donkeys and beats them. But this is not what (20) means. In his approach this problem does not occur, since a farmer-donkey pair is not used here and farmers can be quantified in, which brings along the desired translations. ${ }^{11}$

\section{2. $\forall$-readings and the E-type Strategy}

To account for $\forall$-readings, Chierchia proposes a different approach from the dynamic one that he proposes for $\exists$-readings. His hypothesis is that $\forall$-readings are obtained through the E-type strategy. The

9 For example, (15) is represented as (i).

(i) $\uparrow$ every ( $\lambda \mathrm{x} \downarrow[\mathrm{x}$ is a farmer who owns a donkey]) ( $\lambda \mathrm{x} \downarrow[\mathrm{x}$ is a farmer who owns a donkey and $\mathrm{x}$ beats it]),

where $\downarrow$-operator is used to wipe out place holders.

10 'Conditions' defined in DRT roughly correspond to 'predicates' and 'discourse referents' to 'variables.'

11 DRT also offers a solution for the proportion problem (see Kamp and Reyle (1993)). 
E-type analysis of pronouns has been pursued in various ways (e.g. Heim (1990), Kadmon (1990), Chierchia (1992), Van der Does (1996), and Lappin and Francez (1994)). ${ }^{12}$ In his definition, the E-type strategy is 'a strategy to retrieve through the context the value of unbound pronouns (1995: 113).' More precisely, he assumes that E-type pronouns are functions from individuals to individuals. To show how his theory works, he starts with sentences in which the domains of pronouns are inaccessible to their antecedents.

(21) a. Every man except John gave his paycheck ${ }_{i}$ to his wife. John gave it ${ }_{i}$ to his mistress. (L. Karttunen)

b. It is not true that John doesn't have a car ${ }_{i} . \quad$ It $_{i}$ is parked outside.

In (21a), 'his paycheck' antecedes the pronoun 'it,' but 'it' is not bound by or coreferential with 'his paycheck.' In (21b), 'it' is also inaccessible to 'a car.'

Under the assumption that E-type pronouns are functions from individuals to individuals, the second sentences in (21a) and (21b) are interpreted as in (22), respectively.

(22) a. John gave $f(\mathrm{John})$ to his mistress. ( $f$ : a function from individuals into their paychecks)

b. $f(\mathrm{John})$ is parked outside. ( $f$ : a function from people to their cars)

Chierchia's claim here is that E-type pronouns are sensitive to pragmatic factors, and that they are functions into maximal groups whose domains and ranges are contextually supplied. He extends this E-type strategy to pronouns in donkey sentences having $\forall$-readings. For example, the $\forall$-reading of (1) $(=(23 a))$ is given in $(23 b, c)$, where the dynamic aspects are ignored because of their irrelevance here.

(23) a. Every farmer who owns a donkey beats $_{i}$ it $_{i}$

b. $\forall \mathrm{x}[[\operatorname{farmer}(\mathrm{x}) \wedge \exists \mathrm{y}[\operatorname{donkey}(\mathrm{y}) \wedge \operatorname{own}(\mathrm{x}, \mathrm{y})]] \rightarrow$ beat $(\mathrm{x}, f(\mathrm{x}))]$

12 It can be said that the most prevalent analysis of the E-type strategy is to regard E-type pronouns as some kind of description. Under this assumption, (1) can be analyzed as in (i):

(i ) Every farmer who owns a donkey beats the donkey he owns.

However, in the literature it has been agrued that this analysis has some problems (e.g. Schubert and Pelletier (1989)). 


\section{c. $f$ : a function from farmers to the donkey (or donkeys) they own}

We have seen that in his approach, $\forall$-readings and $\exists$-readings are not accounted for in a uniform way. The E-type strategy is responsible for $\forall$-readings, whereas dynamic bindings account for $\exists$-readings. In other words, he proposes that $\forall$-readings derive from a pragmatic mechanism, whereas $\exists$-readings are from a systematically dynamic one. Donkey sentences have generally only $\forall$ - and $\exists$-readings, and Kanazawa (1994) argues that the fact that one reading is preferred to the other is rather systematic, though pragmatic factors can override the systematic preference. As Chierchia notes, this fact is not inconsistent with his theory. But as Lappin and Francez (1994) put it, it remains as a puzzle why one reading is delivered from a different descriptive apparatus than the other. ${ }^{13}$

\subsection{Problems}

Chierchia's theory has the dynamic bindings (for $\exists$-readings) and the E-type strategy (for $\forall$-readings). In the dynamic bindings, the definitions (11) and (12) divide noun phrases into two groups. That is, indefinites are dynamic in terms of CCPs, while nouns phrases having quantificational determiners are not. (11) and (12) account for the fact that 'it' is bound by the antecedent in (24), but not in (25) and (26). ((24) to (27) are examples from Chierchia (1992)).

(24) Most men that have a donkey beat it $_{i}$.

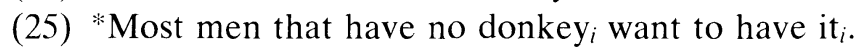

(26) *Most men that have every donkey beat $_{i} \mathrm{it}_{i}$.

Since anaphoric bindings cannot go beyond the syntactic scope of externally static determiners such as 'no' and 'every, ${ }^{1+}$ the pronoun 'it' in

13 Chierchia (1992) indicated the possibility of interpreting the function $f$ as a choice function, a function that arbitrarily selects one of the possible values. But Chierchia discards this idea in this book. The use of choice functions in his theory was also shown to be inadequate by Kanazawa (1994).

1+ Quantificational determiners are internally dynamic (i.e., anaphoric bindings are passed on from indefinites into their right arguments), but externally static (i.e.. they cannot go beyond the syntactic scope of the determiners), while indefinites are internally and externally dynamic. 
(25) and the pronoun 'it' in (26) are left unbound by the antecedents. The same effect also holds in sentences having negation, as shown in (27).

(27) *Most men that do not have a donkey $y_{i}$ want to have $i_{i}$.

His assumption here is that 'not' has a wider scope than the existential operator. Negation, with this assumption, blocks a dynamic extension of the indefinite 'a donkey' in (27).

However, when the E-type strategy is applied to (25) to (27), it is not clear how it deals with their unacceptability. Let's take (27) as an example. In the E-type strategy, it is represented as in (28).

(28) Most $\mathrm{x}[[\operatorname{farmer}(\mathrm{x}) \wedge \neg \exists \mathrm{y}[\operatorname{donkey}(\mathrm{y}) \wedge \operatorname{have}(\mathrm{x}, \mathrm{y})]]$ [want-to-have $(\mathrm{x}, f(\mathrm{x}))$ ]

The problem here is that there is no theoretical strategy to account for the unacceptability of (27). The function $f$ is a function whose range is contextually supplied, and so if there is no restriction on the range of the function, (28) fails to predict that (27) is unacceptable. (One possibility of making such a prediction is to ban the function $f$ from having as its value the donkey (or donkeys) a farmer does not own.)

There is another problem in his approach: it is not always true that quantificational determiners and negation are externally static. There are cases where the determiner 'no' and negation do not seem externally static. Let's consider (29).

(29) Every farmer who does not use a tractor on icy days keeps it in a barn.

The pronoun 'it' is anaphorically linked to the indefinite 'a tractor' in (29). In other words, in (29) the indefinite breaks through the block of negation, which contradicts Chierchia's prediction with the definition (12a). The following are other examples where anaphoric links are possible in spite of the occurrence of 'no' or 'not.'

(30) Most farmers who do not hitch a donkey to a bar put it in a barn.

(31) Every farmer who uses no tractor on icy days keeps it in a barn.

The question to be addressed is what makes the anaphoric links possible in (29), (30) and (31). Let's take (29) as an example. A possible account for it is to assume that the existence of 'tractor(s) that are owned by each farmer' is presupposed in (29), and that the presupposed entities are available as the antecedent for subsequent pronouns. That is, in (29) we are talking about farmers who own their tractor(s) 
and keep it/them in a barn. On the other hand, in $(25)(=(32))$ the existence of donkeys owned by men are not presupposed.

(32) ${ }^{*}$ Most men that have no donkey ${ }_{i}$ want to have it ${ }_{i}$.

The hypothesis of existential presuppositions of the kind that I have proposed predicts that (33) is different from (34) in acceptability, though they are structurally very similar.

(33) * Every boy who reads no book does not buy it.

(34) Every boy who reads no book on the train keeps it in his bookbag.

The main verb phrase in (33) does not presuppose the existence of books each boy has, whereas the one in (34) does or at least can. The existential presupposition is passed on to subsequent pronouns, and this process can be (if we want) easily integrated into Chierchia's treatment of presupposition in a dynamic way.

The phenomena that anaphoric links are possible beyond the block of negation are also observed in non-donkey sentences. Let's compare (35) with (36) and (37).

(35) ${ }^{*}$ John does not have a donkey ${ }_{i}$. He wants it $i_{i}$.

(Chierchia (1995))

(36) John doesn't have a car ${ }_{i}$ anymore. He sold it last month.

(Chierchia (1995))

(37) John wanted to write down what Mary said on the phone, but he could not find a pen ${ }_{i}$ at hand. He did not know that $i_{i}$ was under the desk.

Here too the hypothesis of existential presuppositions works. In (36) and (37), the existence of some car or some pen is presupposed in the second sentence, respectively.

Chierchia's approach requires that (35) be handled by the dynamic binding, while (36) and (37) be handled by the E-type strategy. This dichotomy makes things more complicated when we take the existential presupposition into account. The (existential) presupposition is of dynamic nature, as he points out. Therefore, it can be integrated into his dynamic binding system for $\exists$-readings. However, the E-type strategy to deliver $\forall$-readings is irrelevant to dynamic aspects, and so the existential presupposition needs to be connected to the E-type strategy in another way. This procedure brings complexity into his whole framework.

It might seem that the phenomena we have observed in this section are relevant to the distinction between stage-level predicates and 
individual-level predicates. ${ }^{15}$ As far as the sentences we have seen are concerned, it is possible to generalize that individual-level predicates (such as 'have a donkey') do not allow anaphoric links beyond negative terms, while stage-level ones (such as 'use a tractor') do. However, this generalization does not work in some cases. (38) and (39) are acceptable in spite of the fact that individual-level predicates are used in the relative clauses.

(38) Every man who is not afraid of a mistake won't deny it.

(39) Every dress that doesn't fit a customer is altered for her. ${ }^{16}$

It is unlikely that the distinction between stage- and individual-level predicates is responsible for the fact that anaphoric links are active, in spite of the occurrence of negative terms. ${ }^{17}$

There is another type of sentences where anaphoric bindings under the block of negative terms are possible. It has been pointed out that when pronouns are plural, anaphoric links with them are possible. Let's look at (40).

(40) Most farmers who have no donkeys want to have them. ${ }^{18}$ I have no conclusive idea of how 'them' is related to donkeys that farmers do not own in (40). However, (41) and (42) show that the existential presupposition is relevant to cases where plural pronouns are used.

(41) No student is listening to the lecture. They are lazy.

(42) No one is walking in the park. They are reading a book. In (41) the existence of students attending the lecture is presupposed in the second sentence. The same is true of (42). If there is no such presupposition in (42), (42) sounds odd. ${ }^{19}$ In general, the dynamics of anaphoric bindings linked to plural pronouns is different from the one of anaphoric bindings linked to singular pronouns. I will come back to this issue later.

15 I'd like to thank Barry Shein for drawing my attention to stage/individual-level predicates.

16 (39) is a sentence which originates from Kratzer (1995): "When these dresses don't fit a customer, we will alter them for her."

17 Though this is so, it would be too early to deny the possibility that the distinction of these predicates is relevant to our examples.

18 However, an anaphoric link between 'no $\mathrm{N}$ ( $\mathrm{N}$ is a singular)' and a plural pronoun is not possible, as shown in (i).

( i ) "Most farmers who have no donkey want to have them.

19 I will not go into details because of the limited space. 


\section{Adverbs of Quantification}

In the early stage of the study of donkey sentences, not so much attention was paid to the differences between sentences having relative clauses and those having 'if/when' clauses. But as Heim (1990), Kadmon (1990), Rooth (1992) and many others show, the latter provide more recalcitrant linguistic data for the donkey analysis. In this book, Chierchia tries to handle this by means of combining pragmatic factors like focus with his framework.

His proposal is that determiners be treated as generalized quantifiers, and that unlike quantification in sentences having relative clauses, adverbs of quantification select one or more indefinites as what is quantified over in his approach.

(43) Dolphins are truly remarkable. When a trainer trains a dolphin, she usually makes it do incredible things.

(43) is about dolphins, not about quantification over trainer-dolphin pairs. (43) is true iff most trained dolphins do incredible things. However, if we are talking about trainers, say, trainers's ability to train animals in (43), (43) is true iff most trainers that train a dolphin make it do incredible things. Therefore, what the adverb (= 'usually') selects for quantification depends on what the sentence topic is. This flexibility that sentences with 'if/when' clauses have in selecting entities quantified over stands in sharp contrast with the systematic selection of heads as entities quantified over in sentences having relative clauses.

Now let's look at his analysis more closely.

(44) a. Always, when a cat has blue eyes, it is intelligent.

b. a cat has blue eyes $\Rightarrow \lambda \mathrm{p} \exists \mathrm{x}[\operatorname{cat}(\mathrm{x}) \wedge$ have-blue-eyes $(\mathrm{x})$ $\wedge$ p ]

c. it is intelligent $\Rightarrow \lambda \mathrm{p}$ [intelligent $(\mathrm{x}) \wedge \mathrm{p}$ ]

For the indefinite 'a cat' to be bound by 'always,' we need to get rid of the existential quantifier in (44b). To do so, he uses a technique called 'existential disclosure (ED). ${ }^{20}$ The task of ED is to get entities out of the domination of an existential quantifier by means of putting ' $x$ $=u^{\prime}$ in (44b), as shown in (45).
a. $\exists \mathrm{x} \uparrow[\operatorname{cat}(\mathrm{x}) \wedge$ have-blue-eyes( $\mathrm{x})] \wedge \uparrow \mathrm{x}=\mathrm{u}$
b. $\lambda \mathrm{p} \exists \mathrm{x}[\operatorname{cat}(\mathrm{x}) \wedge$ have-blue-eyes(x) $\wedge \mathrm{x}=\mathrm{u} \wedge \mathrm{p}]$

20) 'Existential disclosure' was developed in P. Dekker (1990). 
Applying the rule of dynamic existential quantifiers (i.e. ' $\exists x \quad A=\lambda p \quad \exists x$ $\left.[A(p)]^{\prime}\right)$ to (45a), we get (45b). After abstracting over $u$ in (45b) to get a property that 'always' can quantify over, we get the translation we want for $(44 a) .{ }^{21}$

(46) a. $\lambda \mathrm{u} \lambda \mathrm{p} \exists \mathrm{x}[\operatorname{cat}(\mathrm{x}) \wedge$ have-blue-eyes( $\mathrm{x}) \wedge \mathrm{x}=\mathrm{u} \wedge \mathrm{p}]]$ $=\lambda \mathrm{x} \uparrow[\operatorname{cat}(\mathrm{x}) \wedge$ have-blue-eyes $(\mathrm{x})]$

b. every' $(\ulcorner\lambda x \uparrow[\operatorname{cat}(\mathrm{x}) \wedge$ have-blue-eyes $(\mathrm{x})])(\sim \lambda \mathrm{x}$ $\uparrow$ intelligent $(\mathrm{x}))$

(47) is an example where a Q-adverb selects more than one indefinite as topics which are quantified over.

(47) a. Always if a woman has a child with a man, she keeps in touch with him.

b. $\forall \mathrm{x}_{i}, \mathrm{x}_{j} \exists \mathrm{x}_{k}\left[\uparrow \operatorname{woman}\left(\mathrm{x}_{i}\right) \wedge \uparrow \operatorname{man}\left(\mathrm{x}_{j}\right) \wedge \uparrow \operatorname{child}\left(\mathrm{x}_{k}\right)\right.$ $\Lambda \uparrow$ has $\left.\left(\mathrm{x}_{i}, \mathrm{x}_{k}, \mathrm{x}_{j}\right)\right]\left[\uparrow\right.$ keep-in-touch-with $\left.\left(\mathrm{x}_{i}, \mathrm{x}_{j}\right)\right]$

As (47) shows, Q-adverbs are treated as polyadic quantifiers in this approach.

\section{Presupposition}

Chierchia extends his theory to presuppositions. He proposes to analyze them from the dynamic perspective that he has developed in terms of donkey sentences. In what follows, I will outline the main idea of his proposals.

In his approach, a sentence $\varphi$ is interpreted in terms of a function $+\varphi$ from context sets to new context sets. Context sets are, by his definition, shared information between agents that can be thought of as a set of worlds compatible with such information. A context set $\mathrm{C}$ is a set that satisfies $\varphi$ 's presuppositions for $\varphi$ to be interpretable in C. In other words, presuppositions are treated as felicity conditions on context sets, and $\varphi$ is an update function.

21 ED yields the desirable results when sentences have quantificational determiners like 'every.'

( i ) a. $\lambda \mathrm{p}[\forall \mathrm{x}[\ldots ..] \wedge \mathrm{p}]$

b. "When every cat has blue eyes, it is usually intelligent.

c. $\lambda u \lambda p[\forall x[\ldots ..] \wedge \mathrm{x}=\mathrm{u} \wedge \mathrm{p}]$

As (i) shows, adding ' $x=u$ ' does not help $x$ to be bound by $\forall$. 
To see his dynamic setting more closely, let's begin with the update function of negative sentences. It is a well-established observation that the presuppositions of a negative sentence $\neg \varphi$ are the same as the ones of $\varphi$. In other words, negation behaves like a "hole."

(48) $\mathrm{c}+\neg \varphi=\mathrm{c}-(\mathrm{c}+\varphi)$,

where for any sets of worlds $a, b: a-b=\{w \in a: w \notin b\}$. (48) means that uttering $\neg \varphi$ in $\mathrm{c}$ amounts to substracting from $\mathrm{c}$ the worlds where $\varphi$ holds. In order to compute $\mathrm{c}+\neg \varphi$, we must first compute $\mathrm{c}+\varphi$. This is why negation is a hole.

The presuppositions of a conjunction are, by contrast, the presuppositions of both conjuncts, unless the first conjunct entails the presuppositions of the second, in which case the presuppositions of the second are "filtered out."

(49) $\mathrm{c}+[\varphi \wedge \psi]=(\mathrm{c}+\varphi)+\psi$

Let's look at a case where the first conjunct entails the presupposition of the second.

(50) Bill likes Mary $(=\varphi)$, and John too likes her $(=\psi)$.

Since $\varphi$ entails $\psi$ 's presupposition, so does $(c+\varphi)$. Then, $\psi$ operates on $(\mathrm{c}+\varphi)$. This process guarantees $\psi$ 's presuppositions to be satisfied.

The difference between ' $c+\varphi$ ' and ' $\lambda \mathrm{p}[\varphi \wedge$ 'p]' is clear: the former represents the initial context in which $\varphi$ is processed, while $\mathrm{p}$ in ' $\lambda \mathrm{p}[\varphi$ $\wedge$ p]' represents what remains open after processing $\varphi$.

\section{Discussion}

We have seen how the dynamics of anaphoric bindings in English is treated in Chierchia's theory. In Japanese too, there is donkey anaphora, but not all aspects of the Japanese anaphora can be accounted for by means of his framework. One of the problems in dealing with Japanese donkey sentences is that they prefer $\exists$-readings to $\forall$-readings. Let's consider (51), where the head NP has 'dono ('every').'

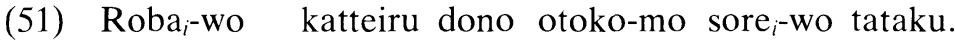
donkey-Acc own every man-Nom Pro-Acc beat 'Every man who owns a donkey beats it.'

The intuition of my Japanese informants is that (51) prefers an $\exists$-reading, though it does not exclude a $\forall$-reading. In general, Japanese donkey sentences, no matter what kind of quantificational force the 
head NPs have, prefer $\exists$-readings, unless pragmatic factors override them to yield $\forall$-readings. This contrasts with English cases, where donkey sentences having $\downarrow \mathrm{MON} \uparrow$ (and $\uparrow \mathrm{MON} \downarrow$ ) determiners such as 'every' in the head NP strongly prefer a $\forall$-reading (see Kanazawa (1994)). ${ }^{22}$ But his framework does not explain why there is such an opposite tendency in terms of preference in readings among languages.

The second problem is that in Japanese there are cases where bare nouns are used in head NP positions or as antecedents of donkey pronouns, as exemplified in (52).

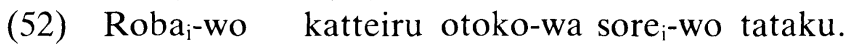
donkey-Acc own man-Top Pro-Acc beat

'Men who own a donkey beat it,'

where 'otoko ('man')' and 'roba ('donkey')' are morphologically bare nouns. In his approach, it is conservativity that plays a crucial role to deliver $\exists$-readings, and existential determiners are determiners that are responsible for passing on the contents of antecedents to donkey pronouns. If 'otoko' and 'roba' in (52) are bare nouns, not generalized quantifiers, his framework does not work for (52). One possible remedy for this problem is to assume that 'otoko' and 'roba' have null determiners. But this method is arguably dubious.

There is another phenomenon that we should take into account. Japanese pronouns behave differently from 'it' in English. They are more like plural pronouns in English. Unfortunately, cases where donkey pronouns are plural are not treated in the book under review.

In what follows, I will briefly discuss these problems, and indicate possible directions for the study of Japanese anaphoric bindings. In section 6.1, I will consider the second problem. The first and third problems will be discussed in section 6.2.

22 Monotonicity is a property that generalized quantifiers have in terms of entailments. Upward and downward monotonicities are defined as follows:

$\uparrow \mathrm{MON}:\left(\mathrm{DAB} \& \mathrm{~A} \subseteq \mathrm{A}^{\prime}\right) \rightarrow \mathrm{DA}^{\prime} \mathrm{B}, \quad \mathrm{MON} \uparrow:\left(\mathrm{DAB}^{\prime} \& \mathrm{~B} \subseteq \mathrm{B}^{\prime}\right) \rightarrow \mathrm{DAB}^{\prime}$

$\downarrow \mathrm{MON}:\left(\mathrm{DAB}^{\prime} \& \mathrm{~A}^{\prime} \subseteq \mathrm{A}\right) \rightarrow \mathrm{DA}^{\prime} \mathrm{B}, \quad \mathrm{MON} \downarrow:\left(\mathrm{DAB}^{\prime} \& \mathrm{~B}^{\prime} \subseteq \mathrm{B}\right) \rightarrow \mathrm{DAB}^{\prime}$ 


\subsection{Indefinites and Bare Nouns}

As we have seen, bare nouns in Japanese are used as antecedents of donkey pronouns as indefinites in English are. The question is whether or not this difference brings about significant problems in Chierchia's approach, and if so, what kind of problems they are. ${ }^{23}$

One of the central issues on indefinites in the literature has been whether they are generalized quantifiers or (some version of) variables. Chierchia stands for the former analysis of indefinites, being affiliated with MG, DPL and GQA, while DRT and FCS stand for the second. But their common understanding of indefinites is that they are noun phrases that have an existential force and a novelty condition, which play a central role in the dynamics of donkey anaphora. However, Japanese bare nouns lack these properties. Let's consider (53).

(53) Otoko $_{i}$-ga haittekita. Otoko ${ }_{i}$-wa yotteita. man-Nom came-in man-Top was-drunk 'A man came in. He was drunk.'

The bare noun 'otoko' in the first sentence introduces a new referent into the discourse. However, if we assume that bare nouns have a novelty condition, we get into trouble with the second sentence, since 'otoko' in the second sentence refers to the referent that has been introduced in the first sentence. This shows that bare pronouns do not satisfy a novelty condition, and that 'otoko' in the second sentence in (53) is not existentially quantified over. (54) is another example that shows that bare nouns have no existential force.

(54) Otoko-ga 3-nin haittekita. man-Nom 3-cl came-in

'Three men came in,'

where 'cl' stands for a classifier. If 'otoko' in (54) is an NP existentially quantified over, (54) would bring about a vacuous quantification. This contradicts the fact that (54) is acceptable. The same problem occurs if we assume that 'otoko' in (54) has a null determiner.

23 In Japanese, antecedents of donkey pronouns are either bare nouns or nouns having (floating) determiners. All the determiners but 'aru (some)' have the form of 'Det-no', where 'no' is genitive. There is no determiner in Japanese that corresponds to the determiner ' $a$ ' in English. 
As we have shown, Japanese bare nouns do not have an existential force or satisfy a novelty condition. But then, what is the semantic content of bare nouns? My proposal is that bare nouns denote a set of individuals as common nouns do. When a sentence has a quantificational determiner that binds a bare noun as in (54), the quantificational force of the sentence is bestowed by the determiner. On the other hand, when a sentence has no such determiner, (i) existential closure is applied to it directly or by means of the dynamics of the existential force, or (ii) a sentence has a (quasi-) universal force. (53) is an example of (i), where the two sentences are open sentences under our assumption. Existential closure is applied to the first sentence, which has an effect that an existential force extends to the second one. This is illustrated in (55). ${ }^{24}$

(55) a. $\exists x[\operatorname{man}(x) \wedge \operatorname{came-in}(x) \wedge p]$

b. $[\operatorname{man}(\mathrm{x}) \wedge \operatorname{drunk}(\mathrm{x}) \wedge \mathrm{p}]$

A typical example of (ii) is (56).

(56) Tori-wa tsubasa-wo motteiru. ('A bird has wings.')

The common treatment of generic sentences such as (56) in the literature is to analyze them as having a (quasi-) universal force (or a generic operator). (57) is an example given by Chierchia (p. 108: see also p. 5).

(57) a. A dog usually barks.

b. most $\left({ }^{\wedge} \lambda \mathrm{x}_{i}\left[\uparrow \operatorname{dog}\left(\mathrm{x}_{i}\right) \wedge \uparrow \mathrm{C}\left(\mathrm{x}_{i}\right)\right]\right)\left({ }^{\wedge} \lambda \mathrm{x}_{i}\left[\uparrow \operatorname{bark}\left(\mathrm{x}_{i}\right)\right]\right)$,

where ED is applied to the NP that has a contextually supplied variable. However, his analysis causes a problem with examples such as (58).

(58) $\mathrm{A} \mathrm{bird}$ has wings. $\mathrm{It}_{i}$ flies.

24 Whether bare nouns are dynamically bound by their antecedents or existentially closed depends on contexts and other linguistic factors. For instance, in (i) existential closure is applied to the second sentence as well as the first one.

(i ) Neko-ga naiteiru. Mukoode-mo, neko-ga naiteiru. cat-Nom be-meowing over-there-too cat-Nom be-meowing 'A cat is meowing. Over there too, a cat is meowing.' 
'Most' is externally static, according to the definition given in section 3.1. This contradicts the fact that 'it' is accessible to 'a bird' in (58). But then, what makes the anaphoric binding possible in (58) ?25, 26

Indefinites in generic sentences, or more generally in sentences having a (quasi-)universal force behave differently from quantificational determiners. Let's consider (59) to (61).

(59) \# Every donkey, if it is female, is placid.

(60) A donkey, if it is female, is placid.

(61) If a theory is classical, then if it is inconsistent, it is trivial.

(Barker (1997))

(59) sounds odd, since (59) implies that each donkey is potentially female. (60) and (61) are, on the other hand, acceptable. ${ }^{27}$ The crucial difference between these sentences is that in (59) the universal force is given by the determiner, 'every,' while in (60) and (61) it derives from genericity (of generic sentences or 'if'-sentences). A similar phenomenon is observed in Japanese quantification, too.

(62) \# Dono roba-mo, mesu-naraba, otonashii.

(63) Roba-wa, mesu-naraba, otonashii.

(64) Riron-ga kotentekide-aru-toki, mujun-ga-aru-naraba, donnashiki-mo-doosyutsu-suru,

where the semantic contents of (62) to (64) correspond to (59) to (61), respectively. ${ }^{28.29}$ Schematically, the sentences having indefinites or

25 A possible (but not so well-motivated) solution to this problem is to assume that (58) is paraphrased with 'A bird has wings and flies' (see Groenendijk and Stokhof (1991) for relevant discussion).

26 One might assume that 'a bird' in (58) denotes a kind as 'dogs' in 'Dogs bark' does. But this assumption causes a problem with sentences such as 'A bird has wings. If it is male, it dances,' where 'male' is not a kind predicate.

27 (61) is an example in Barker (1997), where he discusses some problems on value assignments concerning to 'compound if' sentences. My discussion here is closely related to the problems he brought in, which I will not discuss because of the limit of space.

28 The oddity that the reading of (59) and (62) has is equally observed in sentences having quantificational determiners, as excmplified in (i).

( $\mathrm{i})$ \# Most donkeys, if they are female, are placid.

However, this is not always so. Compare (59) with (ii).

(ii) Every donkey, if it is not hungry, is placid.

A possible way to deal with (ii) is to analyze it as having a quantificational force over situations or events. For example, (ii) is represented as (iii):

(iii) Every $\left(\left[\lambda \mathrm{x} \forall s\right.\right.$ (donkey $(\mathrm{x})$ in $s \rightarrow \diamond \exists s^{\prime}\left(\right.$ not-hungry $(\mathrm{x})$ in $\left.\left.\left.s^{\prime} \wedge s^{\prime} \triangleleft s\right)\right)\right]$, $\left[\lambda \mathrm{x} \exists s^{\prime}\left(\operatorname{placid}(\mathrm{x})\right.\right.$ in $\left.\left.\left.s^{\prime}\right)\right]\right)$. 
bare nouns can be translated as follows (as for (59) and (62), see footnotes 28 and 29):

(65) $\mathrm{A}$, if $\mathrm{B}, \mathrm{C} /$ If $\mathrm{A}$, if $\mathrm{B}, \mathrm{C} \Rightarrow \forall \mathrm{x}(\mathrm{A}(\mathrm{x}) \wedge \mathrm{B}(\mathrm{x}) \rightarrow \mathrm{C}(\mathrm{x}))$ As (65) shows, in sentences having the form " $A$, if $B, C$ " or "if $A$, if $\mathrm{B}, \mathrm{C}$," B is not (quasi-)universally quantified. Though it is not clear exactly what mechanism lies in (59) to (64), these sentences show that in general, donkey pronouns in generic sentences or 'if'-clauses can have an anaphoric relationship with indefinites or bare nouns that are bound by a (quasi-)universal force, with the proviso that the force is not from 'every.' (58), where the anaphoric binding extends to the second generic sentence, also falls under this generalization.

\subsection{Donkey Pronouns}

There are two types of donkey pronouns in Japanese-'sono-N' and 'sore.' ('Sono' is a genitive form of 'sore,' and these pronouns are morphologically unspecified in terms of number.) 'Sono-N' plays the same role as conservativity does in Chierchia's framework. Let's look at (66).

(66) $*$ Roba $_{i}$-wo kattei-nai dono noohu-mo sono donkey-Acc own-Neg every farmer-Nom Pro-Gen roba ${ }_{i}$-wo hoshigaru.

donkey-Acc want-to-have

'Every farmer who doesn't own a donkey wants to have it.' (66) is roughly translated as (67), and (67) explains why (66) is unacceptable.

where $\triangleleft$ stands for a part-of relation, and the $\diamond$-operator handles cases where there happens to be a donkey that is hungry all the time, though it would be placid if it were not hungry. Though (iii) fails to observe compositionality, it does not suffer from the 'double-bind' problem (see Barker (1997) on this problem).

Note that we cannot analyze 'Most A, if $B, C$ ' as 'Most $(A, B \rightarrow C)$ ' As (i) shows, 'Most $\mathrm{A}$, if $\mathrm{B}, \mathrm{C}$ ' requires that every object satisfying $\mathrm{A}$ has a propery of $\mathrm{B}$ in a modal sense. Now, ' $\mathrm{B} \rightarrow \mathrm{C}$ ' requires that every object satisfying $\mathrm{B}$ has to satisfy C. But 'Most (A, C).' When we sum up all these requirements, we get into trouble.

29) Note that since (i) is not logically equivalent to (ii), quantificational determiners cannot be analyzed as having the logical content of (65).

(i ) Most donkeys, if they are hungry, won't move.

(ii) Most hungry donkeys won't move. 
(67) Roba ${ }^{-}$-wo kattei-nai dono noohu-mo [noohu-ga kattei-nai] roba $_{i}$-wo hoshigaru,

which reads 'every farmer who doesn't own donkeys wants to have donkeys [he does not own].'

On the other hand, 'sore' has no effect that 'sore-N' does in (66), as shown in (68).

(68) Roba ${ }_{i}$-wo kattei-nai noohu-wa sore $i$-wo hoshigaru. donkey-Acc own-Neg farmer-Top Pro-Acc want-to-have 'Farmers who don't own a donkey want to have it.'

'Sore' is a syntactic carbon copy of its antecedent noun, so to speak. For example, in (68) 'sore' is coindexed with 'roba ('donkey'),' not with 'noohu-ga kattei-nai roba ('donkey that a farmer does not own').' Another example to show that 'sore' copies its antecedent noun is (69).

(69) $\mathrm{Roba}_{i}$-wo katteiru dono noohu-mo sore $i$-wo maitoshi donkey-Acc own every farmer-Nom Pro-Acc every-year kau.

buy

'Every farmer who owns a donkey buys (other) donkeys every year.'

The preferred reading of (69) is that each farmer buys new donkeys every year, not the same donkeys that he has already owned. Here, the pronoun 'sore' is similar to pronouns of laziness in the sense that it does not refer to the referent(s) that the antecedent introduces in the discourse. Another example of this kind is (70).

(70) Roba $_{i}$-wo katteiru dono noohu-mo sore $i$-wo kawaigaru. donkey-Acc own every farmer-Nom Pro-Acc love 'Farmers who own a donkey loves it.'

(70) does not necessarily mean that each farmer loves only his own donkeys.

Given the data above, the question to be addressed is what semantic role 'sono-N' and 'sore' play. I propose that they be analyzed as predicative variables. This analysis explains, for example, why the determiner 'san-biki ('three-cl') in (71) can bind 'sore.'

(71) Roba $_{i}$-wo katteiru dono otoko-mo sore $i$-wo san-biki donkey-Acc own every man-Nom Pro-Acc three-cl tataku.

beat

'Every man who owns donkeys beats three of them.'

This example shows that the Japanese donkey pronouns are more like 
plural pronouns in English. The English plural pronouns behave differently from singular ones. As (72) and (73) demonstrate, they are accessible to their antecedents, no matter what quantificational force binds the antecedents.

(72) Most farmers who own no donkeys want to have them.

(73) Every farmer who takes care of every donkey that Mary owns loves them.

This is true of Japanese pronouns too, as exemplified in (74).

(74) Hotondo-no roba $i$-wo tataku noohu-wa sono most donkey-Acc beat-Neg farmer-Top Pro-Gen roba $_{i}$-ni kerareru. donkey-by be-kicked

'Farmers who beat most donkeys are kicked by them.'

From what we have discussed, that Japanese donkey sentences prefer an $\exists$-reading is explained straightforwardly: when donkey pronouns are not bound by a determiner, the sentences are existentially closed by means of existential closure (which results in an $\exists$-reading) as bare nouns are. (A possible refinement for this is to introduce a choice function instead of existential closure. We will come back to this issue later.) Note that this does not prevent the sentences from having a $\forall$ reading. However, as is often observed, $\forall$-readings are obtained with the help of floating quantifiers (e.g. 'zenbu ('all')' or 'dore-mo ('all')'). This is why the $\exists$-reading is the default interpretation of Japanese donkey sentences.

Now, the question is how to formulate the mechanism of anaphoric binding in these sentences. Lappin and Francez (1994) is one of the attempts to deal with donkey anaphora by means of E-type accounts with i-sums. ${ }^{30}$ In their approach, donkey pronouns denote functions from individuals to i-sums. In other words, they are interpreted as plural NPs. For example, (75a) is interpreted as (75b).

(75) a. Every man who owns 5 donkeys beats them.

b. $\quad\left(\right.$ Men $\cap\left\{a:\left\{b: *^{*} \operatorname{own}(a, b)\right\} \cap 5\right.$-donkey $\left.\left.\neq \emptyset\right\}\right) \subseteq\{c:$ *beat $(\mathrm{c}, f(\mathrm{c}))\}$,

30) Let A be a set partially ordered by $\square$, and AT a set of atoms in A. Then, for all $a \subseteq b, a$ is a singular individual in A iff $a \in \mathrm{AT} ; a$ is an i-sum otherwise. For example, the students in 'The students gathered for a concert,' which has a collective reading, denotes an i-sum. 
where '5-donkey' represents the set of all and only i-sums of donkeys with cardinality at least 5 , and ${ }^{*}$ own $(\mathrm{x}, \mathrm{y})$ the set of ordered pairs $<a$, $b>$ such that $a$ is an atomic individual, and $b$ is an i-sum which $a$ owns. Lappin and Francez apply to (75) a maximality constraint on $f$ (c) which requires that for each argument $c, f(c)$ selects the supremum in the set of i-sums that is its range (that is, the set of i-sums of at least 5 donkeys which $c$ owns). With this maximality constraint, (75) has an $\forall$-reading.

We obtain the $\forall$-reading of 'Every farmer who owns a donkey beats it' by substituting '5-donkey' in (75b) with '1-donkey.' If we take the function $f$ to be a choice function from individuals to one of the nonmaximal i-sums in its range of values, then we get the $\exists$-reading of this sentence. Lappin and Francez stipulate that in $\exists$-readings, the maximality condition on $f(c)$ is suspended, and a donkey sentence is true iff there is at least one choice function $f(c) .{ }^{31} .32$

In this framework, it is not necessary to assume that bare nouns have a null determiner, and pronouns are treated as if they are plural nouns, which I think is crucial in understanding of the Japanese pronouns.

As we have seen, 'sore' has a different mechanism from 'sono-N' (e.g. in terms of conservativity), and there are more details that we have to consider in Japanese donkey sentences. However, I think that Lappin and Francez (1994), or more generally the semantics of plurality, is a possible and promising direction for the study of Japanese donkey anaphora. But to see how we can develop such a framework that deals with plurality from a more dynamic perspective, we need a more careful investigation of Japanese semantic structure.

31 The problem we have discussed in Section 3.3 occurs in their approach. That is, it cannot deal with sentences such as (31) (=(i)).

( i ) Every farmer who uses no tractor on icy days keeps it in a barn.

32 Landman (1989) proposes a semantics of plurals in which sums are sets of individuals rather than i-sums. Probably his framework is more suitable for the treatment of Japanese donkey pronouns. 


\section{Conclusion}

Chierchia's work in the book under review is an approach to understand linguistic information flow in general in a unified and principled way. He proposes a theory that provides a powerful and elegant framework for $\exists$-readings vs. $\forall$-readings, anaphoric binding in donkey sentences having relative clauses vs. if/when clauses, and presupposition (and as a related issue, definites), inheriting insights and techniques from other dynamic approaches like DRT, FCS, GQA and DPL. But the attraction of this book is not only that: it is designed to account for wide-ranging, and often formidable, linguistic data. In fact, because of his amazingly wide knowledge and understanding of the diversity in natural languages, each corner of the book is full of suggestions and possible directions for more far-reaching (or possibly different) approaches to linguistic phenomena, from syntactic, semantic and pragmatic perspectives.

\section{REFERENCES}

Barker, Stephen (1997) "E-Type Pronouns, DRT, Dynamic Semantics and the Quantifier/Variable-Binding Model," Linguistics and Philosophy 20, 195228.

Barwise, Jon and Robin Cooper (1981) "Generalized Quantifiers in Natural Language," Linguistics and Philosophy 5, 159-220.

Chierchia, Gennaro (1992) "Anaphora and Dynamic Binding," Linguistics and Philosophy 15, 111-183.

Dekker, Paul (1993) "Existential Disclosure," Linguistics and Philosophy 16, 561-587.

Groenendijk, Jeroen and Martin Stokhof (1991) "Dynamic Predicate Logic," Linguistics and Philosophy 14, 39-100.

Heim, Irene (1982) The Semantics of Definite and Indefinite Noun Phrases, Doctoral dissertation, University of Massachusetts, Amherst. [Published by Garland, New York, 1982.]

Heim, Irene (1990) "E-type Pronouns and Donkey Anaphora," Linguistics and Philosophy 13, 137-178.

Does, Jaap van der (1996) "An E-Type Logic," Logic, Language and Computation, ed. by Jerry Seligman and Dag Westerståhl, 555-570, Center for the Study of Language and Information, Stanford.

Kadmon, Nirit (1990) "Uniqueness," Linguistics and Philosophy 13, 273-324.

Kamp, Hans (1981) "A Theory of Truth and Discourse Representation," Formal Methods in the Study of Language, ed. by Jeroen Groenendijk, Theo 
Janssen, and Martin Stokhof, 277-322, Mathematical Centre, Amsterdam. Kamp, Hans and Uwe Reyle (1993) From Discourse to Logic, Dordrecht, Kluwer.

Kanazawa, Makoto (1994) "Weak vs. Strong Readings of Donkey Sentences and Monotonicity Inferences in a Dynamic Setting," Linguistics and Philosophy 17, 109-158.

Kratzer, Angelika (1995) "Stage-Level and Individual-Level Predicates," The Generic Book, ed. by Greg Carlson and Jeff Pelletier, 125-175, University of Chicago Press, Chicago.

Landman, Fred (1989) “Groups, I," Linguistics and Philosophy 12, 559-605.

Lappin, Shalom and Nissim Francez (1994) "E-Type Pronouns, I-Sums, and Donkey Anaphora," Linguistics and Philosophy 17, 391-428.

Pagin, Peter and Dag Westerståhl (1993) "Predicate Logic with Flexibly Binding Operators and Natural Language Semantics," Journal of Logic, Language, and Information 2, 89-128.

Schubert, Lenhart and Francis J. Pelletier (1989) "Generally Speaking," Properties, Types and Meaning, ed. by Barbara Hall Partee, Gennaro Chierchia and Raymond Turner, Vol. II, 193-268, Kluwer, Dordrecht.

Department of Foreign Studies

Nagoya Gakuin University

1350 Kamishinano, Seto-shi

Aichi 480-1214

e-mail: imani@ngu.ac.jp 